\title{
ANALISIS PENERAPAN PROGRAM MITIGASI BENCANA PADA BADAN PENANGGULANGAN BENCANA DAERAH
}

\author{
Pandu Sakti ${ }^{1}$, Faizal Anwar ${ }^{2}$, Rekho Adriadi ${ }^{3}$ \\ Universitas Muhammadiyah Bengkulu ${ }^{1,2,3}$ \\ faizalanwar@umb.ac.id ${ }^{2}$
}

\begin{abstract}
ABSTRAK
Tujuan penelitian ini adalah bagaimana implementasi kebijakan badan penanggulangan bencana Provinsi Bengkulu dalam mitigasi bencana. Metode penelitian ini menggunakan penelitian deskriptif kualitatif. Hasil penelitian menjelaskan bahwa implementasi kebijakan Badan Penanggulangan Bencana Daerah (BPBD) Provinsi Bengkulu untuk pelaksanaan kebijakan mitigasi bencana sudah berjalan cukup baik. Badan Penanggulangan Bencana Daerah Provinsi Bengkulu dalam Mitigasi Bencana sudah mengeluarkan kebijakan dalam mengurangi risiko bencana diantaranya adalah kebijakan Desa tangguh Bencana dan persentase sekolah aman Bencana. Selain menjalankan kebijakan tersebut Badan Penanggulangan Bencana Daerah Provinsi Bengkulu juga melaksanakan kegiatan sosialisasi kesiapsiagaan bencana. Dalam pelaksanaan kebijakan ini juga berkerjasama dengan instansi lain untuk melaksanakan kegiatan atau kebijakan dalam menciptakan Provinsi Bengkulu aman dari bencana. Simpulan penelitian ini menunjukkan bahwa kebijakan yang dikeluarkan BPBD Provinsi Bengkulu dalam Mitigasi telah diatur dalam Peraturan Gubernur Nomor 34 Tahun 2018 tentang peningkatan kesiapsiagaan. Diantaranya adalah kebijakan desa tangguh bencana dan Sekolah Madrasah aman bencana.
\end{abstract}

Kata Kunci: Bencana, Kebijakan, Mitigasi

\begin{abstract}
The purpose of this research is the implementation of policies of the Bengkulu Province disaster management agency in disaster mitigation. This research method uses descriptive qualitative research. The results of the study explained that the implementation of policies of the Bengkulu Province Regional Disaster Management Agency (BPBD) for the implementation of disaster mitigation policies had been running quite well. The Regional Disaster Management Agency of Bengkulu Province in Disaster Mitigation has issued a policy on natural disaster reduction, namely the Disaster Resilient Village policy and the proportion of Disaster safe schools. Apart from implementing this policy, the Bengkulu Province Disaster Management Agency also carries out socialization activities for disaster preparedness. In implementing this policy, we also cooperate with other agencies to carry out activities or policies in making Bengkulu Province safe from disasters. The conclusions of this study indicate that the policies issued by the Bengkulu Province BPBD in Mitigation are regulated in Governor Regulation Number 34 of 2018 concerning increased preparedness. Among them are disaster-disaster village policies and disastersafe Madrasah schools.
\end{abstract}

Keywords: Disaster, Mitigation, Policy. 


\section{PENDAHULUAN}

Pelaksanaan kebijakan BPBD Provinsi Bengkulu dalam mitigasi bencana sudah diatur dalam Peraturan Gubernur Nomor 34 Tahun 2018-2022 tentang rencana penanggulangan bencana di Provinsi Bengkulu Tahun 2018-2022, pada Bab IV (4) tentang kebijakan penanggulangan bencana menjelaskan sasaran dan kebijakan Badan Penanggulangan Bencana Daerah yang bertujuan untuk meningkatkan kesiapsiagaan penanggulangan bencana. (Ariyanti, 2015)

Pelaksanaan kebijakan yang diterapkan oleh Badan Penanggulangan Bencana Daerah Provinsi Bengkulu untuk menjalankan mitigasi bencana sudah diatur dalam Peraturan GubernurNomor 34 Tahun 2018-2022 tentang rencana penanggulangan bencana Provinsi Bengkulu tahun 2018-2022 menjelaskan ada empat (4) arah kebijakan sebagai berikut : persentase desa tangguh bencana, persentase sekolah aman bencana, persentase ketersediaan peta risiko bencana skala besar, dan jumlah Perundang-undangan penanggulangan bencana. Selain itu ada juga program dan kegiatan Badan Penanggulangan Bencana Daerah Provinsi Bengkulu diantaranya sebagai berikut: memfasilitasi desa tangguh bencana, memfasilitasi sekolah aman bencana, sosialisasi pengurangan risiko bencana bagi siswa/siswi SD sampai SMA di daerah rawan bencana, kerja sama dengan perguruan tinggi untuk pengurangan risiko bencana, dan penyebaran informasi potensi bencana alam. (Darmi, 2020)

Provinsi Bengkulu adalah salah satu Provinsi yang ada di Indonesia, Provinsi yang salah satunya sering terdampak bencana alam seperti, gempa bumi, longsor, banjir, angin puting beliung dan tsunami. Untuk menciptakan masyarakat Provinsi Bengkulu menjadi masyarakat yang kesiapsiagaan maka perlu adanya kesinambungan antar instansi baik itu pemerintah maupun instansi non pemerintah. Karena koordinasi setiap instansi itu sangat penting untuk meciptakan manajemen yang baik dalam melaksanakan kebijakan mitigasi bencana. Ini bukan hanya tugas BPBD semata tapi ini juga tugas setiap instansi yang ada di Provinsi Bengkulu baik itu pemerintah, LSM dan masyarakat harus bekerja sama untuk menciptakan Provinsi Bengkulu menjadi masyarakat yang siap siaga bencana. (Dunn, 2003)

Berdasarkan pemaparan yang ada di atas, maka peneliti tertarik untuk mengangkat sebuah penelitian yang berjudul "Analisis Implementasi Kebijakan Badan Penanggulangan Bencana Daerah Provinsi Bengkulu Dalam Mitigasi Bencana". Rumusan masalah peneliti angkat adalah bagaimana implementasi kebijakan Badan Penanggulangan Bencana Daerah Provinsi Bengkulu Dalam Mitigasi Bencana.

\section{METODE PENELITIAN}

Penelitian ini dilaksanakan di Badan Penanggulangan Bencana Daerah Provinsi Bengkulu Jln.P. Natadirja Km 7 Kota Bengkulu. Penelitian ini digunakan oleh peneliti adalah penelitian deskriptif kualitatif. Teknik pengumpulan data dalam penelitian ini yaitu observasi, wawancara dan dokumentasi. Observasi dilakukan dengan secara pengamatan langsung di Badan Penanggulangan Bencana Daerah Provinsi Bengkulu. Sedangkan wawancara yang dilakukan dengan menyiapkan terlebih dahulu pertanyaan-pertanyaan atau wawancara yang sesuai dengan inti dari permasalahan yang akan diteliti nanti. Analisis data yang digunakan dalam penelitian ini adalah teknik analisis data menurut Miles dan Huberman yang meliputi tahap-tahap seperti reduksi data, penyajian data dan pemberian kesimpulan dan verifikasi. (Moleong, 2011)

\section{HASIL PENELITIAN}

Penelitian ini ingin melihat bagaimana implementasi kebijakan Badan Penanggulangan Bencana Daerah Provinsi Bengkulu. Pada penelitian ini yang menggunakan konsep implementasi kebijakan dari Van Mater dan Van Hord, teori ini memiliki enam indikator diantaranya sebagai berikut: (1) Standar dan sasaran kebijakan; 
(2) Sumber daya; (3) Hubungan organisasi; (4) Karakteristik agen pelaksana; (5) Kondisi sosial, ekonomi dan politik; (6) Disposisi.

\section{PEMBAHASAN}

\section{Standar dan Sasaran Kebijakan}

Dalam pelaksanaan kebijakan sasaran dan tujuan kebijakan itu harus jelas, maka dari itu sasaran kebijakan dan standar sudah diatur dalam Peraturan Gubernur Nomor 34 Tahun 2018 tentang rencana penanggulangan bencana di Provinsi Bengkulu ada empat (4) kebijakan yang dikeluarkan BPBD Provinsi Bengkulu yaitu desa tangguh Bencana, sekolah aman bencana. tersedianya peta risiko bencana dan perundang-undangan penanggulangan bencana. (Pratama, 2017)

Hal di atas diperjelas lagi oleh Kepala Badan Penanggulangan Bencana Daerah Bapak Dr. Rusdi Bakar sebagai berikut :

"Sasaran kebijakan sudah diatur Peraturan Gubernur 34 tahun 2018-2022 di sana menjelaskan sasaran kebijakan yang akan kami lakukan untuk mengatasi bencana alam yang terjadi di Provinsi Bengkulu. Salah satu kebijakan mitigasi bencana adalah sosialisasi kemasyarakatan agar tahu bagaimana cara mengatasi bencana yang terjadi di daerah yang rawan bencana" (Wawancara 25 juli 2019).

Adapun menurut Kepala bidang Prabencana Bapak Rustam Efendi kepada peneliti menjelaskan :

"Untuk sasaran kebijakan adalah masyarakat yang terdampak bencana, bukan hanya itu saja kami juga membuat poster, brosur, gladi bersih dan sosialisasi kepada masyarakat supaya masyarakat tau pentingnya pengetahuan tentang mitigasi bencana supaya masyarakat paham dengan tindakan pertama yang harus dilakukan". (Wawancara, 25 Juli 2019)

Dari data di atas sudah menjelaskan bahwa dari kebijakan mitigasi bencana yaitu desa tangguh bencana dan sekolah aman bencana sudah cukup baik. Kebijakan tersebut salah satunya desa tangguh bencana. Dilihat dari penyajian data target Badan Penanggulangan Bencana Daerah tahun 2019 memiliki target $60 \%$ desa tangguh bencana dari keseluruhan desa yang rawan bencana sebanyak 373 desa tapi yang sudah terbentuk hanya $118(45 \%)$ desa masih ada $255(55 \%)$ desa tangguh bencana yang belum terbentuk. Sasaran dari mitigasi bencana adalah untuk meningkatkan kesiapsiagaan masyarakat tentang penanggulangan bencana, dan di dalam Peraturan Gubernurnomor 34 tahun 2018 juga dijelaskan arah kebijakan yang akan dilakukan dalam mitigasi bencana. (Hasani, 2015)

\section{Sumber Daya}

Untuk menjalankan kebijakan tersebut makan perlu adanya sumber daya baik itu sumber daya manusia atau sumber daya finansial. Sumber daya yang paling berperan adalah sumber daya manusia Apartur Sipil Negara (Darmi dkk, 2017). Sumber daya tersebut sangat penting dalam melaksanakan kebijakan yang telah ditentukan dan sumber daya juga bisa menentukan keberhasilan suatu kebijakan tersebut. Hal itu diperjelas kembali oleh Bapak Dr. Rusdi Bakar sebagai berikut:

"Untuk menjalankan kebijakan tersebut SDM sangat perlu karena keberhasilan kebijakan tersebut tergantung kualitas SDM baik itu yang SDM yang ada di kantor maupun yang ada di lapangan supaya menciptakan masyarakat yang kesiapsiagaan" (Wawancara 26 Juli 2019).

Dari hasil kesimpulan bahwa sumber daya manusia harus bisa menjalankan kebijakan yang telah ditentukan. Kita bisa melihat sumber daya manusia (SDM) di tabel 4.8 menjelaskan bahwa SDM yang ada di Badan Penanggulangan Bencana Daerah. Bukan hanya dari BPBD saja tapi juga ada sekitaran 1500 orang siap membantu melaksanakan kebijakan Badan Penanggulangan Bencana Daerah. 
Untuk melaksanakan kebijakan tersebut bukan hanya sumber daya manusia saja yang penting ada juga sumber daya finansial atau anggaran yang harus diperhatikan dalam melaksanakan kebijakan Badan Penanggulangan Bencana Daerah dalam melaksanakan mitigasi bencana. Pada wawancara di atas dijelaskan bahwa sumber daya finansial yang belum terlalu optimal, kita bisa melihat dari kebijakan mitigasi bencana di bidang desa tangguh bencana belum mencapai target yang telah ditentukan BPBD. Maka dari itu BPBD meminta Pemerintah Daerah lebih meningkatkan kembali sumber daya finansial atau anggaran. Dengan adanya sember daya finansial atau anggaran yang meningkat maka akan lebih mengoptimalkan terlaksananya kebijakan tersebut. (Setyowati, 2017)

\section{Hubungan Antara Organisasi}

Pelaksanaan suatu kebijakan akan berjalan efektif apabila adanya komunikasi yang baik antar stakeholder yang berhubungan dengan kebijakan tersebut. Menurut Van Meter dan Van Hord mengatakan komunikasi yang dimaksud adalah adanya saling kerja sama antar organisasi baik itu pemerintah maupun organisasi lain dalam menjalankan kebijakan tersebut. Hal tersebut diperjelas oleh Bapak Dr. Rusdi Bakar sebagai berikut:

"Untuk menjalankan kebijakan tersebut perlu adanya kerja sama antar stakeholder baik itu pemerintah maupun non pemerintah supaya implementasi kebijakan tersebut bisa dicapai yaitu menciptakan masyarakat yang siapsiaga" (Wawancara 25 Juli 2019) .

Dalam pelaksanaan kebijakan Badan Penanggulangan Bencana Daerah Provinsi Bengkulu komunikasi harus berjalan dengan baik dalam menjalin kerja sama dengan instansi yang terkait. Badan Penanggulangan Bencana Dearah BPBD Provinsi Bengkulu tidak akan bisa melaksanakan kebijakan mitigasi bencana dengan sendirinya. Maka dari itu harus ada kerja sama antara stakehorder baik itu Pemerintah Kota Provinsi Bengkulu maupun instansi non pemerintahan contohnya PMI, masyarakat, perguruan tinggi dan media.

Dengan komunikasi yang sudah cukup baik di setiap stakeholder dalam meningkatkan kerja sama baik itu mensosialisasikan kebijakan mitigasi bencana dan pelatihan kesiapsiagaan bencana, maka dari itu terciptalah masyarakat Provinsi Bengkulu masyarakat yang siapsiaga terhadap bencana yang akan melanda.

\section{Karakteristik Agen Pelaksanaan}

Berdasarkan hasil observasi peneliti pada Badan Penanggulangan Bencana Daerah (BPBD) Provinsi Bengkulu, berupa dokumen tentang bencana alam dapat disimpulkan bahwa kebijakan sangat berpengaruh dengan agen pelaksana. Agen pelaksana BPBD Provinsi Bengkulu sangat penting dalam keberhasilan kebijakan sosialisasi kepada masyarakat agar siapsiaga ketika terjadi bencana alam. Untuk agen pelaksana itu tidak kalah penting di sini agen pelaksana adalah orang-orang yang berpengalaman dalam hal bidang bencana alam supaya apa agar waktu sosialisasi ke masyarakat bisa menerima dengan baik apa yang disampaikan.(Daryono, 2018)

Agen pelaksana tidak kalah pentingnya dalam melaksanakan kebijakan BPBD dalam mitigasi bencana. Pernyataan di atas menunjukkan bahwa agen pelaksana sudah mencukupi dalam melaksanakan kebijakan mitigasi bencana. Dikarenakan jika agen pelaksana yang berpengalaman tentang bencana dan sudah terlatih maka dalam melakukan sosialisasi kepada masyarakat agen pelaksana bisa menjelaskan tentang kesiapsiagaan atau mitigasi bencana kepada masyarakat dengan benar dan masyarakat bisa memahami dan mengerti dengan penjelasan dari agen pelaksana itu sendiri. (Bakornas, 2006)

\section{Kondisi Ekonomi, Sosial dan Politik}

Kondisi dan lingkungan harus diperhatikan dalam melakukan sosialisasi kepada masyarakat Badan Penanggulangan Bencana Daerah harus tau kondisi lingkungan tersebut. Bagaimana kondisi dan lingkungan masyarakat yang di kawasan yang rawan 
bencana, bukan hanya kondisi lingkungan saja tapi juga kondisi ekonomi masyarakat di situ kita tahu. Untuk melakukan sosialisasi kami harus memeriksa terlebih dahulu tempat tersebut apa benar di daerah tersebut benar terdampak bencana. untuk melakukan sosialisasi harus melihat faktor-faktor contohnya apa di situ banyak wanita lanjut usia, ibu hamil dan anak-anak. (Anwar, 2019)

Kebanyakan masyarakat di Provinsi Bengkulu yang tempatnya rawan bencana itu kebanyakan petani dan wirausaha kita tau sendiri kesibukan mereka, untuk dari itu Badan penanggulangan Bencana Daerah harus pas melihat hari apa saja masyarakat bisa melaksanakan sosialisasi biar warga yang berada ditempat tidak merasa dirugikan karena ikut dalam sosialisasi kesiapsiagaan bencana atau mitigasi bencana. (Wahab, 2015)

\section{Sikap Para Pelaksanaan/Disposisi}

Sikap penerima atau disposisi keberhasilan atau kebijakan hal tersebut dapat terjadi, apabila kebijakan bukan hasil formulasi dari kebijakan warga di daerah tersebut. Pengetahuan pelaksana kebijakan dalam pelaksana tersebut sangat diperlukan. (Said, 2017)

Dari pelaksanaan kebijakan mitigasi bencana ini yang paling sulit, dikarenakan untuk membangun jiwa kesadaran untuk peduli dengan keselamatan itu sangatlah penting. Terkadang masyarakat tidak merespon dengan sosialisasi tentang kesiapsiagaan bencana banyak anak muda yang tidak peduli dengan kegiatan ini, kita juga bisa melihat kebanyakan yang datang kegiatan tersebut ada ibu-ibu dan masyarakat yang sudah tua. Hal ini diperjelas kembali oleh Bapak Dr. Rusdi Bakar sebagai berikut:

"Sikap ini sangat diperlukan dalam menjalankan kebijakan tersebut dikarenakan kita bisa melihat bagaimana reaksi masyarakat bisa menerima atau tidak selama sosialisasi tersebut. Apakah mereka bisa memahami apa yang diberikan oleh agen pelaksana tersebut. Karena membangun kesadaran jiwa masyarakat itu sangatlah sulit". (Wawancara, 25 Juli 2019)

Ini adalah tantangan bagi badan penanggulangan bencana daerah BPBD bagaimana membangun karakter masyarakat supaya sadar pentingnya mitigasi bencana itu sendiri waktu terjadinya bencana alam.

\section{Upaya Mengatasi Kendala Yang Dihadapi Dalam Mitigasi Bencana}

Dari penjelasan di atas di halaman 88 kendala yang dihadapi dalam kebijakan mitigasi bencana adalah kesadaran diri. Maka untuk mengatasi kendala yang dihadapi BPBD dalam melaksanakan kebijakan mitigasi bencana maka Badan Penanggulangan Bencana daerah (BPBD) mengeluarkan kebijakan atau program sosialisasi di sekolah-sekolah, supaya menanamkan kesadaran diri dari dini supaya dari kecil sudah ditanamkan jiwa kesadaran tentang kesiapsiagaan tentang kebencanaan yang terjadi jika melanda daerah yang kita tinggal. Bukan hanya materi tentang kesiapsiagan saja tapi juga akan ada pelatihan bagaimana jika terjadi bencana, mereka akan diajarkan dan praktik langsung bagaimana mengatasi bencana jika terjadi. (Nugroho, 2003)

Penjelasan di atas juga menerangkan bukan hanya kendala tentang kesadaran diri saja tapi juga ada kendala yang dihadapi BPBD dalam kebijakan mitigasi bencana yaitu tentang sumber daya finansial atau anggaran. Untuk mengatasi kendala yang dihadapi Kepala Bidang Pra Bencana Bapak Rustam Efendi menjelaskan bahwa anggaran terus kami minta dengan Pemerintah Kota Provinsi Bengkulu menaikkan sumber daya finansial atau anggaran dalam pelaksanaan mitigasi bencana supaya tidak terhambat dalam melaksanakan kebijakan mitigasi bencana.

\section{SIMPULAN}

Kebijakan yang dikeluarkan BPBD Provinsi Bengkulu dalam mitigasi telah diatur dalam Peraturan Gubernur Nomor 34 Tahun 2018 mempunyai sasaran adalah meningkatkan kesiapsiagaan. Badan Penanggulangan Bencana Daerah Provinsi Bengkulu 
sudah mengeluarkan kebijakan dalam mengurangi risiko bencana diantaranya adalah kebijakan desa tangguh bencana dan Sekolah Madrasah aman bencana. Dalam melaksanakan kebijakan ini Sumber Daya Manusia (SDM) dan Sumber Daya Finansial sangat penting, maka dari itu perlu adanya kerja sama dengan instansi lain baik itu instansi Pemerintahan maupun instansi Non Pemerintah. Untuk menciptakan masyarakat Provinsi Bengkulu Siapsiaga bencana harus ada komunikasi antara stakeholder.

Kendala yang dihadapi kebijakan mitigasi Bencana adalah Masalah kesadaran diri terhadap siapsiagaan bencana. karena masyarakat biasanya tidak merespon dengan kegiatan yang dilakukan baik itu BPBD maupun instansi lainnya melaksanakan sosialisasi mitigasi bencana, bukan hanya faktor kesadaran diri saja tapi faktor sumber daya finansial juga mendukung terhambatnya sosialisasi tentang mitigasi bencana. dikarenakan masyarakat lebih memilih bekerja dari pada ikut serta dalam sosialisasi tentang mitigasi bencana.

\section{DAFTAR PUSTAKA}

Anwar, F. (2019). Analisis Kebijakan Publik. Rumah Cetak Vanda. Bengkulu Ariyanti, I. H. (2015). Implementasi Kebijakan Penanggulangan Bencana. Universitas Airlangga

Bakornas, P. B. (2006). Panduan Pengenalan Karakteristik Bencana dan upaya Mitigasi di Indonesia, Badan Koordinasi Nasional Penanganan Bencana. Jakarta

Darmi, T., \& Suwitri, S. (2017). Strengthening the Capacity of Human Resources Apparatus in the Implementation of New Autonomous Regions. European Journal of Social Sciences, 55(4), 427-438

Darmi, T., Mujtahid, I. M., \& Udin, U. (2020). Capacity Planning Of The New Autonomous Region In. Humanities \& Social Sciences Reviews, 8(1), 691-698

Daryono, D. (2018). Pendalaman Materi Geografi Modul 12 Bencana Alam. Jakarta

Dunn, W. N.(2003). Pengantar Analisis Kebijakan Public. Gajah Mada University press: Yogyakarta

Hasani, F. (2015). Peran Badan Penanggulangan Bencana Daerah Kabupaten Bantul Dalam Mitigasi Bencana Alam. Tesis. Universitas Islam Negeri Sunan Kalijaga. Yogyakarta

Moleong, J., L. (2011). Metode Penelitian Kualitatif. PT Remaja Rosdakarya. Bandung

Nugroho, R. (2003). Kebijakan Publik: Formulasi, Implementasi Dan Evaluasi. Jakarta: Elex Media Komputindo

Pratama, G., Tarigan, J., \& Nursanty, N.(2017). Analisis Penanggulangan Bencana Banjir Oleh Badan Penanggulangan Bencana Daerah (BPBD) Kota Bengkulu (Doctoral dissertation, Universitas Bengkulu)

Said, A., Z. (2012). Kebijakan Publik. Edisi 2. Salemba Humanika: Jakarta

Setyowati, A. C. (2017). Implementasi Kebijakan Penanggulangan Bencana Pada Tahap Tanggap Darurat. Semarang: Universitas Diponegoro

Van Meter, D. S., \& Van Horn, C. E. (1975). The Policy Implementation Process: A Conceptual Framework. Administration \& Society, 6(4), 445-488

Wahab, S. A. (2015). Analisis Kebijakan Publik. PT. Bumi Aksara, Jakarta

Wahab, W. (2006). The Policy Implementasi Process Conceptual Framework Administration And Society 